\title{
Epigenetics modifiers: potential hub for understanding and treating neurodevelopmental disorders from hypoxic injury
}

\author{
Ana G. Cristancho ${ }^{1,2}$ and Eric D. Marsh ${ }^{1,2^{*}}$ (D)
}

\begin{abstract}
Background: The fetal brain is adapted to the hypoxic conditions present during normal in utero development. Relatively more hypoxic states, either chronic or acute, are pathologic and can lead to significant long-term neurodevelopmental sequelae. In utero hypoxic injury is associated with neonatal mortality and millions of lives lived with varying degrees of disability.

Main body: Genetic studies of children with neurodevelopmental disease indicate that epigenetic modifiers regulating DNA methylation and histone remodeling are critical for normal brain development. Epigenetic modifiers are also regulated by environmental stimuli, such as hypoxia. Indeed, epigenetic modifiers that are mutated in children with genetic neurodevelopmental diseases are regulated by hypoxia in a number of preclinical models and may be part of the mechanism for the long-term neurodevelopmental sequelae seem in children with hypoxic brain injury. Thus, a comprehensive understanding the role of DNA methylation and histone modifications in hypoxic injury is critical for developing novel strategies to treat children with hypoxic injury.

Conclusions: This review focuses on our current understanding of the intersection between epigenetics, brain development, and hypoxia. Opportunities for the use of epigenetics as biomarkers of neurodevelopmental disease after hypoxic injury and potential clinical epigenetics targets to improve outcomes after injury are also discussed. While there have been many published studies on the epigenetics of hypoxia, more are needed in the developing brain in order to determine which epigenetic pathways may be most important for mitigating the long-term consequences of hypoxic brain injury.
\end{abstract}

Keywords: Hypoxia, Brain development, Neurodevelopmental disorders, Epigenetics, DNA methylation, Histone modification

\section{Background}

The in utero environment is a hypoxic environment compared to ambient conditions. Early in the first trimester, partial pressure of oxygen is as low as $20 \mathrm{mmHg}$ in the placenta and only rises to about $50 \mathrm{mmHg}$ during

\footnotetext{
* Correspondence: marshe@email.chop.edu

${ }^{1}$ Departments of Neurology and Pediatrics, Perelman School of Medicine at the University of Pennsylvania, Philadelphia, USA

${ }^{2}$ Division of Child Neurology, Children's Hospital of Philadelphia, Philadelphia, USA
}

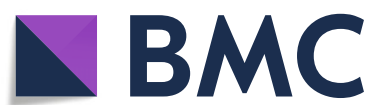

(c) The Author(s). 2020 Open Access This article is licensed under a Creative Commons Attribution 4.0 International License, which permits use, sharing, adaptation, distribution and reproduction in any medium or format, as long as you give appropriate credit to the original author(s) and the source, provide a link to the Creative Commons licence, and indicate if changes were made. The images or other third party material in this article are included in the article's Creative Commons licence, unless indicated otherwise in a credit line to the material. If material is not included in the article's Creative Commons licence and your intended use is not permitted by statutory regulation or exceeds the permitted use, you will need to obtain permission directly from the copyright holder. To view a copy of this licence, visit http://creativecommons.org/licenses/by/4.0/. The Creative Commons Public Domain Dedication waiver (http//creativecommons.org/publicdomain/zero/1.0/) applies to the data made available in this article, unless otherwise stated in a credit line to the data. of oxyoen is $100 \mathrm{mmHg}$ postnatally) [1]. These baseline hypoxic conditions are likely required for normal brain development, as exposure to the ambient environment (i.e., relative hyperoxia) can cause brain injury in premature infants (reviewed in [2]). While exposing the premature brain to high oxygen tension is damaging, further decreasing oxygen levels in pregnancy also leads to significant injury to the developing brain. Worldwide, hypoxic brain injury in preterm and term neonates accounts 
for many newborn deaths and millions of years lived with disability [3-5]. Neurodevelopmental disorders (NDD) that can be caused by prenatal and perinatal hypoxic injury include developmental and intellectual disabilities, cerebral palsy, autism, and epilepsy.

Hypoxic injury occurs across a spectrum but can be divided into two major categories: chronic and acute. Despite their differing mechanisms of injury, the NDDs caused by chronic and acute hypoxia encompass the entire spectrum of NDDs but are quite variable at the level of the individual patient. Chronic in utero hypoxia is secondary to environmental factors, including high altitude, maternal factors contributing to placental insufficiency (e.g., obesity, smoking, diabetes, or drug use), and fetal factors (e.g. congenital heart disease) [6]. Chronic in utero hypoxia likely contributes to intrauterine growth restriction and is related to increased risk of prematurity; the leading cause of neonatal morbidity and mortality worldwide $[4,5,7,8]$. There are a number of preclinical models of chronic hypoxia, including rearing pregnant and postnatal animals in hypoxic conditions, exposure to factors that promote placental insufficiency, or mid to late gestation uterine artery ligation [9-11]. These models have demonstrated that chronic hypoxia is correlated to white matter injury similar to what is seen in humans with preterm brain injury.

Hypoxic ischemic encephalopathy (HIE), also known as perinatal asphyxia and neonatal encephalopathy, occurs in 1-6 per 1000 births and is considered to be due to a relatively brief loss of oxygen and nutrients at the end of gestation [3]. The etiology of HIE is varied; it can include sudden events like placental abruption or more indolent events like intermittent umbilical cord compression [3]. It accounts for $23 \%$ of neonatal deaths worldwide and nearly half of the surviving children will have abnormal neurodevelopmental outcomes from this injury $[5,12]$. The most commonly used model of neonatal HIE is the Rice-Vannucci model where unilateral carotid ligation is performed at postnatal day 8-10 (P810) rodents and animals are subsequently exposed to 8$10 \%$ fraction of inspired oxygen for $1-2 \mathrm{~h}\left(\mathrm{FiO}_{2}\right)[9,13]$. This is a hybrid model of HIE and focal stroke but has provided important insights into the pathophysiology of HIE. Other post-natal hypoxia only models have also been used to study neonatal seizures and cerebral palsylike motor dysfunction $[9,14]$.

Initial mechanisms of injury for chronic and acute hypoxia are thought to be a result of metabolic dysregulation that leads to significant cell death. In humans, this can only be studied in the most severe cases via postmortem pathology studies [15], in which the cell death could have occurred after death or is reflective of an atypically severe process. If there is significant cell death, estimated indirectly in surviving children by the burden of diffusion restriction seen in brain magnetic resonance imaging, there is likely to be significant neurologic sequelae from injury $[15,16]$. However, it is clear even if there is not significant cell death, surviving neurons and glial cells continue to have abnormal structure and dysfunction long after in utero hypoxic brain injury, which dictates long-term neurologic outcomes [17, 18]. Longlasting injury to surviving cells is likely due to the unique combination of injury superimposed on a critical period of brain development.

An attractive unifying hypothesis linking prenatal hypoxia to the persistent functional and structural deficits of many different cells in the brain is that prenatal hypoxia permanently alters the epigenome [19-22]. The epigenome is the profile of transcription factors and histone and DNA modifications that dictate cell identity and function without altering the genetic code and it is extensively regulated during normal development [19-22]. Several mutations in epigenetic modifiers can lead to a variety of NDDs [23, 24], and the epigenome can be regulated extensively by environmental inputs, such as perinatal stressors [19-22]. This review will give a brief overview on epigenetic mechanisms important for brain development, with focus on the potential roles of epigenetic modifiers in dictating outcomes after hypoxic brain injury during development that overlap with genetic NDDs, and opportunities to use epigenetics to predict neurodevelopmental outcomes or as therapeutic targets for improving neurodevelopmental outcomes.

\section{Primer on epigenetic modifications}

The epigenome plays a critical role in development by orchestrating which genes are active during all stages of maturation $[25,26]$. DNA methylation and histone modifications, two of the predominant epigenetic modifiers (often called epigenetic marks), dynamically change starting from embryogenesis [27, 28] (Fig. 1a). Coordination of these epigenetic marks throughout the course of development forms identifiable epigenetic trajectories that are thought to be critical for cell maturation and specification [25, 29, 30] (Fig. 1b).

\section{DNA methylation}

DNA methylation is an extensively regulated epigenetic mark during development and throughout the life of a cell [31-33]. DNA methylation occurs at the $5^{\prime}$ position of the nucleotide cytosine (5'-methylcystine, $5 \mathrm{mC}$ ). DNA methyltransferases (DNMTs) are required for methylation. Early research hypothesized that this mark was irreversible (reviewed in [34]). More recently, though, demethylation has been demonstrated to be catalyzed by ten-eleven translocation family proteins (TETs); this enzyme promotes conversion from $5 \mathrm{mc}$ to 5 '-hydroxymethylcytosine $(5 \mathrm{hmC})$, which can ultimately 


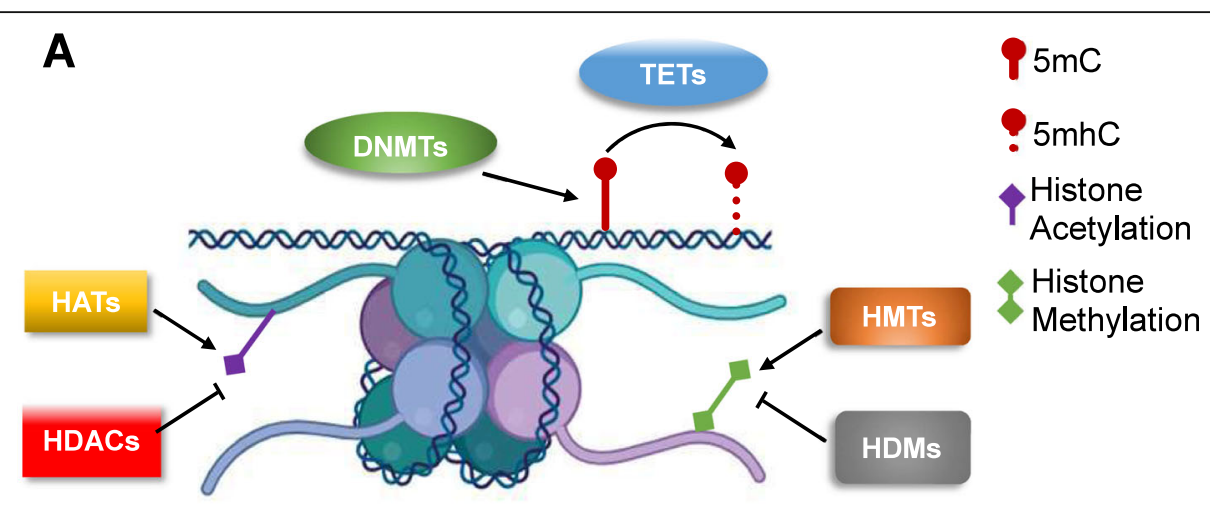

B

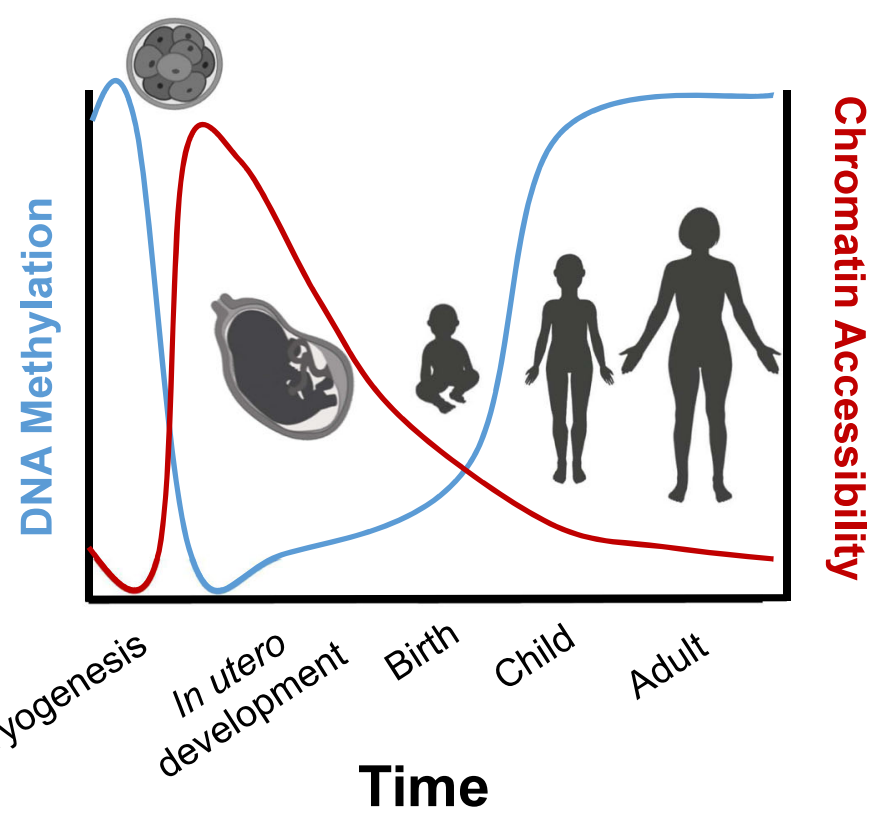

Fig. 1 There are multiple layers of epigenetic gene regulation that are tightly regulated during development. a The epigenetic landscape is dictated by a number of modifications to DNA and histones as indicated in legend. The primary modification to DNA is DNA methylation on the nucleotide cytosine (5' methylcyrtosine, $5 \mathrm{mC}$ ) by DNA methyltransferases (DMNTs). Methylated DNA can also be demethylated in a multistep process. The first step in this process is conversion of $5 \mathrm{mC}$ to $5^{\prime}$-hydroxymethylcystosine by ten-eleven translocation family proteins (TETs). At the histone level, histones can be covalently modified at multiple locations. The most common modifications are acetylation and methylation (lesser understood and not shown are histone phosphorylation and ubiquitination.) Histone acetylation is regulated by histone acetyltransferases (HATs) and histone deacetylases (HDACs). Histone methylation is regulated by histone methyltransferases (HMTs) and histone demethylases (HDMs). The balance of histone methylation of demethylation at different histone residues dictates chromatin accessibility. b DNA methylation and chromatin accessibility are tightly regulated during the course of brain development throughout the lifespan. While there are not direct studies comparing DNA methylation and chromatin accessibility in the same brain samples during development, here we schematize a summary of known studies that demonstrate a near inverse relationship between extent of DNA methylation (blue line) and chromatin accessibility (red line) over time

actively be converted to cytosine through thymine DNA glycosylase-mediated base excision repair (reviewed in [35-37]). Demethylation by TETs are vital immediately after fertilization when both the genome of the maternal and paternal DNA are almost completely demethylated to become totipotent stem cells $[38,39]$. TETs may play an important role in mature brain function as well; analysis of human postnatal tissues reveals that the brain has the highest levels of $5 \mathrm{hmC}$ content pointing to a lifelong dynamic regulation of methylation [40]. Supporting these ideas are studies by Mills and colleagues that demonstrate that $5 \mathrm{mC}$ and $5 \mathrm{hmC}$ are dynamically changing during human fetal brain development both globally and at specific loci [41, 42].

The exact role of DNA methylation in epigenetic regulation of transcription has become more complicated in recent years. The most extensively studied form of methylation occurs when cytosine is directly followed by guanine (known as CpG or CG sites) (reviewed in [28, 31]). When CG sites are clustered, they are known as 
CG islands. Methylation of CG islands is typically associated with gene silencing $[28,31]$. However, in the brain there is also extensive non-CG methylation, particularly in neurons (known as $\mathrm{CH}$ where the " $\mathrm{H}$ " nucleotide $=\mathrm{A} / \mathrm{C} / \mathrm{T})[32,43]$. While in some locations, methylated $\mathrm{CH}$ sites are associated with $\mathrm{CG}$ islands and DNA repression, in other areas they are associated with genes escaping $\mathrm{X}$-inactivation and transcriptional activation [32, 43] (and reviewed in $[44,45]$ ). During the course of brain development and maturation, there is a gradual accumulation of $5 \mathrm{mC}$ at CG and $\mathrm{CH}$ sites; thus, the role of DNA methylation in modulating transcription and neurodevelopmental disease is likely related to the balance between $5 \mathrm{mC}$ and $5 \mathrm{hmC}$ at specific CG and $\mathrm{CH}$ sites [32].

\section{Histone modifications}

Histone modifications form a possibly more complicated regulation of transcription than DNA methylation due to the extensive number of modifications that can take place on the nucleosome. In brief, nucleosomes are comprised of two copies each of four histone subunits: histone 2A $(\mathrm{H} 2 \mathrm{~A})$, histone $2 \mathrm{~B}(\mathrm{H} 2 \mathrm{~B})$, histone $3(\mathrm{H} 3)$ and histone $4(\mathrm{H} 4)$. A linker protein, histone $1(\mathrm{H} 1)$, is recruited between them. When DNA is "tightly wound" around these structures, it is not accessible to transcriptional activators. However, covalent modifications to specific lysines $(\mathrm{K})$ or arginines $(\mathrm{R})$ to these histones can alter how tightly DNA is bound to the genome. For example, dimethylated (me2) or trimethylated (me3) histone 3 lysine 9 (H3K9) and H3K27me3 are marks for transcriptional repression but acetylation (ac) of H3K9 and H3K27 are associated with transcriptional activation (reviewed in $[21,25,46]$ ).

The ultimate read out from these modifications is chromatin accessibility. Greater accessibility is correlated to increased transcriptional activation since DNA is not only more accessible to transcription factors, but also to the transcriptional machinery, such as RNA polymerase [21, 25, 46]. Accessibility can be profiled in the genome through high throughput sequencing techniques which assess level of expression of genes around known epigenetic marks or more globally. Using these techniques in an organoid model of forebrain development, Pasca and colleagues recently demonstrated that chromatin accessibility patterns change throughout development differently in neurons and glia [30]. In particular, during early development of these organoids, there is a burst of increased chromatin accessibility, which may be related to periods of relative demethylation that has been observed in embryonic stem cell systems. As cells continue to mature, cell-type specific motifs continue to remain more accessible. For example in neurons, motifs near regulators of synaptic function remained more open in mature cells than motifs near genes important for neural differentiation or proliferation [30]. Interestingly, this early increase in accessibility was more obvious in neuron lineages than in glial lineages. It is unclear if this discrepancy is related to organoid differentiation of different glial cells or truly reflects in vivo development.

Genome accessibility is regulated by a large number enzymes that add/remove these covalent modifications, including histone acetyltransferases (HATs), deacetylates (HDACs), histone methyltransferases, and demethylases. Each of these proteins regulate the histone code through association with transcriptional activators or repressors (extensively reviewed in $[25,26,47,48])$. The complex regulation of this intricate histone code allows for exquisite regulation of transcription in response to developmental and environmental stimuli that are important to understand neurodevelopmental outcomes from genetic and acquired disorders.

\section{Epigenetics in brain development-lessons from neurogenetics}

The advent, and clinical implementation, of massively parallel sequencing has resulted in a dramatic evolution in our understanding of the genetics of neurodevelopmental disease. By discovering the genetic etiologies of intellectual disability, autism, and epilepsy, we have obtained important insights into the pathways that are critical for brain development and function.

Interestingly, while over 1000 genes with de novo mutations in patients with NDDs have been discovered, a review by Eichler and colleagues highlighted that there are three pathways that have emerged as central nodes for mutations in patients with NDDs: chromatin remodeling, wingless (WNT) signaling, and synaptic function [49]. Two of these pathways, chromatin remodeling and WNT signaling, are direct modulators of the epigenome and transcriptional regulation thus highlighting the importance of epigenetics in neurodevelopmental disease. Neuronal activity, albeit more indirectly, also regulates the epigenetic landscape in neurons, thus strengthening the hypothesis that regulation of the epigenome is central to normal brain development [50,51].

Several of the epigenetic modifiers in which mutations (pathogenic variants) are associated with NDDs are also regulated by hypoxia or can regulate the hypoxic response (Table 1). This link between epigenetic modulating genes associated with the NDDs and normal brain development, suggests that epigenetic changes due to environmental insults (in this case hypoxia) may be vital to understanding the mechanism of HIE. Indeed, these epigenetic pathways may be key to improving our 
Table 1 List of epigenetic modifiers that are mutated in children with developmental disorders but have also been described as mediators of the hypoxic response

\begin{tabular}{lll}
$\begin{array}{l}\text { Overlap between genetic developmental disorders and hypoxic } \\
\text { response }\end{array}$ \\
\hline DNA methylation & Histone modifications \\
\hline DNMT3A & CHD7 & HDAC4 \\
DNMT3B & CHD8 & KMT2D \\
MeCP2 & P300 & KDM6A \\
\hline
\end{tabular}

treatments of NDDs from multiple etiologies. Below we will highlight lessons from genetic disorders in DNA methylation and histone modifications that may provide insight into the hypoxic response during prenatal and perinatal injury.

\section{DNA methylation in genetic NDDs}

In addition to their role during embryonic development, there is extensive evidence from genetic disorders that dynamic methylation and demethylation processes continue to have important functions in postnatal brain function. First, DNMT3A, which is a rare cause of a syndromic NDD, is expressed at high levels in post-mitotic neurons and oligodendrocytes throughout maturation into adulthood [52, 53]. DNMT3A null mice have decreased survival in the early postnatal period, and mice lacking DNMT1 and DNMT3A in post-mitotic neurons have deficits in hippocampal size, learning, and memory [54]. DNMT3A but not DNMT1 is required for the maintenance of $\mathrm{CH}$ methylation in mature cortex [43]. DNMT3B is also mutated in syndromic neurodevelopmental disease, although it seems to have a limited role in murine brain development so we have a more limited understand of its role in brain development and function [55]. Interestingly, there are no TETs mutated in human disease and TET-deficient mice are not embryonic lethal, which may indicate these are critical enzymes specifically for human development or there are other enzymes that can compensate for loss of function (reviewed in [35, 36]).

Recognition of DNA methylation binding is also important for development. Methyl-CpG-binding protein 2 (MeCP2), which is mutated in Rett Syndrome-one of the most common causes of severe intellectual disability with autistic features in girls (but rarely in boys)-has a high affinity for binding at methylated DNA at CG islands and recruiting transcriptional repressors for gene silencing in the brain $[56,57]$. However, in a recent review, Kinde et al. described extensive work on how $\mathrm{MeCP} 2$ can also bind $\mathrm{CH}$ sites and $5 \mathrm{hmC}$. This $\mathrm{CH}$ binding suggests that $\mathrm{MeCP} 2$ may have a diverse capacity to finely regulate transcription in the post-mitotic neurons [45] further highlighting the importance of different forms of epigenetic marks during development and in the mature brain.

\section{Histone modifications in genetic NDDs}

Different mutations that have been found in patients with NDDs implicate almost every aspect of histone structure and remodeling as important factors for brain development [49]. One of the first described epigenetic gene mutations in autism was in the chromatin domain helicase DNA-binding proteins (CHD) 7 and 8. CHD7 and CHD8 are ATP-dependent chromatin remodeling proteins with different functions despite their similar names. CHD7, which is associated with CHARGE syndrome (coloboma of the eye, heart defects, atresia of the nasal choanae, retardation of growth and development, genital and urinary abnormalities, and ear abnormalities and deafness), colocalizes to active genes and is important for hippocampal neurogenesis [58, 59]. By contrast, CHD8 is mutated in non-syndromic autism and is thought to recruit $\mathrm{H} 1$ and lead to transcriptional repression of targets like p53 and $\beta$-catenin during development, implicating histone organization in regulating brain function and directly linking chromatin remodeling to WNT pathway regulation [60,61].

Furthermore, modifiers of the histone modification code (both acetylation and methylation) have been implicated in children with genetic NDDs. RubinsteinTaybi syndrome, a craniofacial syndrome with intellectual disability, is associated with the histone acetyltransferase (HAT) p300 [62]. This highly conserved HAT is near ubiquitous and binds to dozens of transcription factors to increase chromatin accessibility and promote gene expression, giving it a critical function in a number of developmental processes including brain development (reviewed in [63, 64]). More recently histone deacetylase 4 (HDAC4) was implicated in children with intellectual disability [65]. Lastly, Kabuki syndrome, a syndromic NDD with constellation of distinct facial and skeletal anomalies, consists of mutations in one of two opposing regulators of histone methylation: lysine-specific methyltransferase 2D KMT2D and the Jumonji C-domain protein lysine-specific demethylase 6A (KDM6A) [66]. The similar phenotype between these functionally opposing factors highlights that the epigenetic landscape needs balanced regulation of epigenetic marks for normal brain development and function.

Given the rapid expansion of this field, as we gain further insight into genetic causes of NDDs and more insights into the role of epigenetic modulators in cell type-specific brain development we will better understand how these epigenetic mechanisms regulate celltype specific functions in the mature brain, during 
development, and even how these modifiers effect the brain's response to hypoxic injury.

\section{Epigenetics in hypoxic brain injury}

In addition to the epigenetic progression that occurs as part of normal development, the epigenetic landscape of the developing brain is responding to external signals from the maternal-placental environment, including maternal diet or stress and placental health (reviewed in [67]). Epigenetic modifiers are also critical in mediating the response to a hypoxic in utero environment. The canonical response to a hypoxic environment is induction of hypoxia inducible factor 1 alpha (HIF1 $\alpha$ ), a transcriptional activator that is stabilized by hypoxia and critical to a cell's compensatory response to low oxygen conditions [68]. HIF1 $\alpha$ targets are diverse and are responsible for promoting angiogenesis and hematopoiesis, regulating metabolic demand, and increasing nutrient uptake to preserve cell survival [68]. The role of HIF1 $\alpha$ in HIE as a protective or deleterious factor has been controversial with reports of conflicting reports [69, 70]. These differences are likely due to experimental issues, such as timing of the insult and when HIF1 $\alpha$ is stabilized or inhibited, indicating there may be a delicate balance between HIF1 $\alpha$ requirements for normal development and HIF $1 \alpha$ dose-dependent effects between compensatory and pathologic responses to hypoxic insult.

Regulation of HIF1 $\alpha$ activity by epigenetic modifiers is critical to the response of many cell types to hypoxic insult (extensively reviewed in by multiple sources [68, 71-73]. The HIF1 $\alpha$ promoter itself may be regulated by CG and $\mathrm{CH}$ methylation, contributing to its abundance in a cell [74]. Additionally, the HIF1 $\alpha$ response element (sequence 5'-RCGTG-3') contains a CG site and methylation at these sites dramatically alters the affinity of HIF1 $\alpha$ to these binding sites [75]. HIF1 $\alpha$ also directly upregulates expression of several of the Jumonji chromatin demethylases [76]. While methylation of HIF1 $\alpha$ targets have not been studied in the developing brain, accessibility to HIF $1 \alpha$ binding sites during different stages of development and in different cell types may account for the ability of the brain to compensate for hypoxic injury, particularly in regulating Jumonji C-domain proteins. Many of the same epigenetic modifiers and processes implicated in children with genetic causes of NDDs have also been implicated in the cellular response to hypoxia, including some evidence that they may be involved in hypoxic brain injury.

\section{DNA methylation and hypoxic injury}

Numerous lines of evidence point to the impact of hypoxia on DNA methylation. The interplay between hypoxia and methylation have largely been studied in the context of chronic hypoxic exposure, such as in high altitude, sleep apnea, or cancer. However, even relatively brief hypoxia exposure in cultured hippocampal neurons leads to lasting changes in DNA methylation [19]. Different regions of the genome are hypermethylated and hypomethylated in the setting of hypoxia. DNMT3B is induced in ovine uterine arteries by chronic gestational hypoxia and associated with a hypermethylation of BKCa channel beta-1 subunit, a potassium channel subunit [77]. It is unknown if the fetal brain has similar changes in response to changes in oxygen tension in the placenta. Furthermore, populations that live at high altitude have regions of increased and decreased methylation at genes associated with compensatory response to hypoxia [78]. Prenatal stress as also been associated with changes in methylation. One of the changes that was observed was hypomethylation of p300 in children who experience prenatal stress, raising the question as to whether prenatal stress dysregulates this intellectual disability gene [79]. It is important to note that human studies are from peripheral blood samples, which may demonstrate a significantly different pattern of methylation than what is observed in brain tissue. In tumor cells, hypoxia is associated with general hypermethylation due to the repression of TET activity. However, chronic in utero hypoxia is related to global DNA hypomethylation of the brain in rodents, indicating the need for further studies in the developing brain to determine the tissue-specific response to hypoxic injury [80].

Abnormalities in DNA methylation may provide a mechanistic explanation for the epidemiological link between chronic and acute hypoxic insult to the developing brain. One potential link is through regulation of MeCP2 activity. The role of hypoxia has also been studied in the setting of Rett syndrome since children with Rett syndrome have irregular breathing patterns possibly leading to transient post-natal hypoxia [81-83]. Children with Rett and MeCP2-deficient mice have increased oxidative stress burden indicating metabolic dysfunction could play a role in pathophysiology of this disorder [81, 84, 85]. Antenatal risk factors in HIE include factors such as maternal illicit drug use and excess weight gain, which would place the fetus in an environment of chronic hypoxia prior to an acute insult [86]. To test the contribution of chronic in utero hypoxia as a primer for worsening HIE outcomes, Zhang and colleagues exposed pregnant rats to continuous $10 \% \mathrm{FiO}_{2}$ from embryonic day $15-21$ and then performed Rice-Vannucci paradigm at P10 [87]. Animals exposed to chronic prenatal hypoxia have significant worsening of infarct size that is related to methylation and subsequent repression of the glucocorticoid receptor by MeCP2 [87]. Consistent with this finding, pretreating rats with azacitidine, a DNA methylation inhibitor, also predisposes rats to larger infarct volumes after HIE [80]. Worsening of an acute 
hypoxic injury after chronic hypoxia may be unique to the developing brain as hypoxic preconditioning protocols in adult stroke models decreases infarct volume [88].

However, acute hypoxia alone may also regulate $\mathrm{MeCP} 2$ activity. In adult transient ischemia there is an increase in MecP2 levels [89]. Hypoxia-induced seizures in neonatal rats leads to increase MeCP2 phosphorylation at serine 421 and treating seizures abrogates MeCP2 phosphorylation [90]. This post-translational modification decreases spine density in the setting of $\mathrm{MeCP} 2$ overexpression, a pathological state [91]. Future studies of hypoxia in the setting of $\mathrm{MeCP}^{\mathrm{S} 241 \mathrm{~A}}$ mutant would help determine if long-term deleterious effects of hypoxia-related neonatal seizures can be mitigated by inhibiting MeCP2 phosphorylation.

These findings bring forth interesting questions. First, are there other regions of the genome that are effected by chronic antenatal stress that "prime" the response to more significant hypoxic insult later in gestation? Second, since the in utero environment is more hypoxic at baseline, does HIE have other direct effects on methylation status of neurons and support cells without priming by a prenatal stressor? Lastly, do chronic and acute hypoxia differentially effect the balance between $5 \mathrm{mC}$ and $5 \mathrm{mhC}$ at $\mathrm{CG}$ or $\mathrm{CH}$ sites and what is the final effect skewing of the methylation status have on gene expression in the human brain? Better understanding these questions may allow us to determine if intervening on antenatal factors affect neurodevelopmental outcomes in HIE by minimizing damage from an acute hypoxic insult.

\section{Histone modifications and hypoxic injury}

By regulating transcription through HIF1 $\alpha$, hypoxia undoubtedly has significant effects on histone mark patterns at the loci of its targets. Many of the histone modifying genes have been shown to have important roles in regulating the hypoxic response in various cell types. CHD7, which regulates neurogenesis, is repressed in hypoxic-ischemic microenvironments of glioblastoma cells, indicating it might regulated in other hypoxic states during development [59, 92]. KMT2D hypomorphic cells and knockout mice have an increased stabilization of HIF1 $\alpha$ but decreased expression of hypoxia genes, indicating the KMT2D may be a critical component of the HIF1 $\alpha$ transcriptional activation machinery [93]. While there have not been studies of specific HDACs in models of HIE, the pan HDAC inhibitor sodium butyrate in adult stroke models promotes neurogenesis in the hippocampus [94, 95]. Sodium butyrate may be mediating this affect as an anti-inflammatory or by promoting expression of brain-derived neurotrophic factor in neurons and support glial cells $[95,96]$.
Recently, there has been exciting work on the role of HIF1 $\alpha$-independent regulation of chromatin by hypoxia. Histone methylation is increased by hypoxia in a number of cell lines independent of HIF1 $\alpha$ stabilization [97]. This regulation may be mediated by Jumonji $C$ domain proteins, which are in a superclass of proteins known as 2-oxoglutarate and Fe (II)-dependent dioxygenases (2OGDs) (reviewed in [98]). The 2-OGDs superclass also includes the prolyl hydroxylase required for HIF $1 \alpha$ stabilization under hypoxic conditions, thus other enzymes from this class also have the ability to directly respond to hypoxic conditions. KDM6A was recently described as a 2-OGD protein capable of acting as an oxygen sensor independent of HIF1 $\alpha$, making it an attractive candidate to study in the setting of hypoxic brain injury [99].

While there are not many studies of most of these epigenetic modifiers in pre-natal or perinatal hypoxic brain injury, we now have ample evidence justifying studies in hypoxic brain injury. By using clinically relevant disease models, we may (1) acquire a more precise understanding of the roles of epigenetic modifiers in brain development, (2) understand how the modifiers may be disrupted differentially during develop by environmental insults, and (3) develop novel therapeutic strategies.

\section{Other opportunities for future studies and interventions}

Epigenetic modifiers have important roles in a number of other diseases, including cancer, metabolism, and cardiovascular disease $[31,72,100,101]$. Therefore, as we increasingly appreciate the important roles of epigenetic regulation in normal brain development and function, we are able to leverage a number of tools that have already been developed by other fields to expedite clinical translation of epigenetics as both a biomarker of disease and therapeutic target (Fig. 2).

\section{Epigenetic biomarkers}

Methylation abnormalities in the setting of perinatal disease have recently garnered increased interest as a biomarker for neurodevelopmental outcome/diseaseseverity in the neonatal period as well as in the longterm. Preterm neonates that had atypical performance on the NICU Network Neurobehavioral Scale had differential methylation at almost 30 loci in blood samples [102]. Consistent with the possibility that peripheral DNA methylation status can be a biomarker for neurodevelopmental outcomes, in a small study of newborn blood spots in monozygotic twins that eventually were discovered to be discordant for cerebral palsy, researchers identified differentially methylated regions between affect and unaffected siblings [103].

Furthermore, the methylation clock has been used as a measurement for maturation and can be used to 


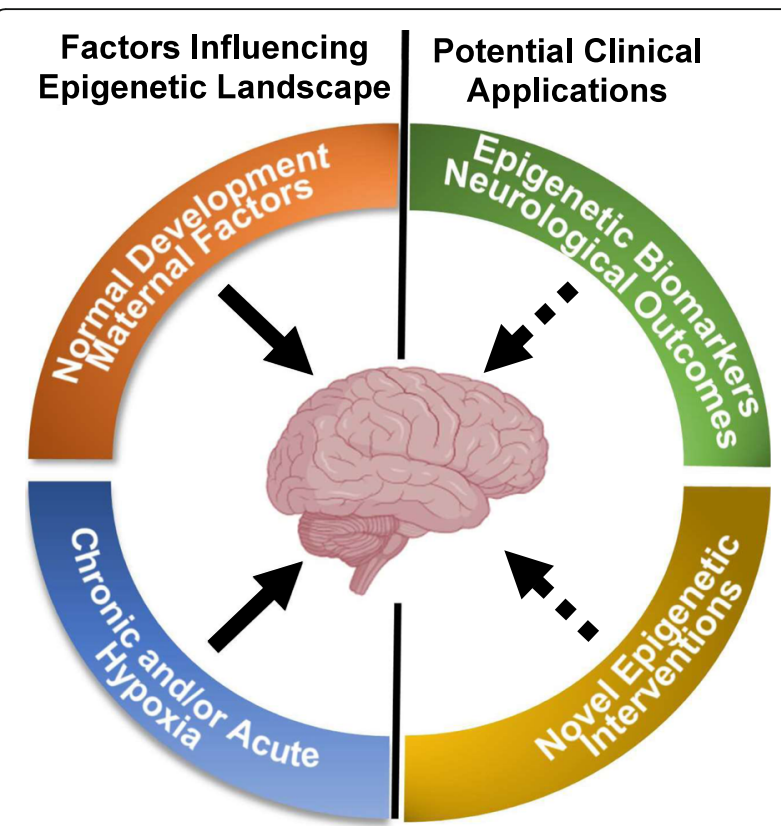

Fig. 2 Epigenetic modifiers may allow for clinical insight into developmental hypoxic brain injury. The developing human brain is influences throughout the course of development by a number of extrinsic (i.e., maternal/placental factors) and an intrinsic developmental program. Chronic and acute hypoxic stress during in utero development are also likely to alter the epigenome, and effect the ultimate maturation of function of the brain leading to neurodevelopmental disorders. By further understanding the role of the epigenome in brain development and mature brain function, we hope to determine better biomarkers for neurodevelopmental disease after prenatal injury. We can also take advantage of a number of compounds that have been developed to modulate the epigenome for other diseases to rapidly develop novel therapeutics to improve cognitive outcomes from hypoxic injury

approximate gestational age at birth as well as biology age, known as the "epigenetic age" [104-106]. In humans, epigenetic age is slowed in umbilical cord blood after prenatal stress [79]. Changes from prenatal stress may be sustained at some portions of the genome for up to 13 years [107]. Studies that validate these markers in different populations and across different ethnic groups are still needed. Importantly, it is not clear if these methylation differences can be modified in order to be used as markers for potential therapeutic interventions.

\section{Epigenetics as a target in neurodevelopmental disease}

Epigenetic modifiers are highly tractable to pharmacologic interventions, with many medications currently under development for cancers and neurodegenerative disorders (reviewed in [23, 100, 108]). Epigenetic targeted therapeutics have successfully rescued neurocognitive deficits in models of Rett and Kabuki syndromes $[109,110]$. Interestingly, approach in neither disease has focused on directly modifying the genome. For Rett syndrome, MeCP2 overexpression can lead to as many neurological sequelae as the deletion, therefore most approaches have focused on modulation of diverse downstream pathways, including signaling and metabolic pathways [110]. In a preclinical trial for Kabuki syndrome, Dietz and colleagues treated Kmt6d-deficient mice with the HDAC inhibitor AR-42 in the juvenile period, reasoning that the mutation led to a favoring of closed chromatin state that would be counteracted with HDAC inhibition. Remarkably, despite the mutation being present throughout development, AR-42 rescued memory deficits in mutant mice [109]. Similarly, neurogenesis is impaired in in CHD7-null mice but can be rescued by increasing the amount the animals exercise on a voluntary running wheel [59]. Exercise is thought to promote epigenetic remodeling of the promoter of brain derived neurotrophic factor, an important regulator of neurogenesis and myelination [111-113]. These studies provide compelling evidence that epigenetic modulators may be viable targets for treating neurocognitive deficits and that the window for treating NDDs may extend past early development.

HDACs in general are attractive targets for hypoxic brain injury. However, many studies are needed to determine the effects of medications like sodium butyrate on neurocognition after administration in the perinatal period. Valproic acid, a commonly used anti-epileptic that is also an HDAC inhibitor, is controversial in the neonatal period [114]. Some studies report a neuroprotective effect in rodents in the setting of HIE, while other report significant increases in cell death and behavioral deficits in control animals when the drug is administered in the neonatal period $[115,116]$. It is important to note that all valproic acid studies used 2-5 times the upper limit of valproic acid that is typically used in patients, limiting their interpretation for the clinical setting. However, sodium butyrate has also been shown to induce senescence and apoptosis in cancer cells, thus using this medication in neonates requires significant testing in preclinical models of chronic hypoxia and HIE [117].

TETs may also be an attractive target to study in prenatal brain hypoxic brain injury. In a model of adult stroke, Tet3 was induced in the penumbra of infarcted tissue [118]. Tet3-deficiency was associated with worsening of the infarct. Thus, stabilizing these proteins may be a viable strategy for neuroprotection. TET induction would be an attractive hypothesis to explain the global hypomethylation of DNA seen after chronic in utero hypoxia if it indeed is not critical to brain development as suggested in animal studies. However, further studies are needed to determine whether this hypomethylation phenomenon is due to a change in the balance of DNMTs and TETs and if it is indeed a protective mechanism as seen in stroke [80]. As we continue to unravel the mechanisms underlying TETs and other epigenetic 
modifiers, we will likely be able to develop novel intervention strategies that are targeted appropriately to different ages of brain maturation.

\section{Conclusions}

In summary, the regulation of many aspects of the epigenome are critical for normal in utero brain development and continue to be important in the mature brain. The continually emerging clinical genetic data linking mutations in epigenetic-involved genes in children with various genetic etiologies of the NDDs, including autism, epilepsy, and intellectual disability emphasizes the importance of these epigenetic process in normal brain development. Mechanistic studies have illustrated that these modifiers have multiple roles in brain development as well as in modulating the brain's response to environmental stressors, such as pathologic chronic and acute in utero hypoxia. By using an array of tools, including genetic models and high throughput profiling, we have an opportunity to understand which epigenetic modifiers are most important for regulating hypoxic injury and which pathways are most affected by insults to the developing brain. Ultimately, the pathways that regulate and are regulated by the epigenome are potential hubs for understanding and modulating neurodevelopmental sequelae from hypoxic brain injury.

Further studies with current technologies will allow us to understand the roles of the epigenome in mediating both injury and recovery from hypoxia in specific cell types. Cell type-specific models and single-cell profiling studies may allow us to understand how the epigenetic modifiers described in this review may change throughout development, how these same regulators may be affected by hypoxia, and how hypoxia leads to neurological disease. Studying the cell-specific effects of candidate epigenetic controller genes, will determine which cell types are most affected by hypoxia and could be targeted for intervention. Gaining a temporal understanding of the role of these candidate epigenetic controller genes, will allow for a tailored understanding of both the pathogenesis and treatment of either chronic or acute hypoxic injury. Systematic study of therapies targeting the epigenome by globally altering the balance of DNA accessibility has the potential to provide a vast clinical pipeline of agents to improve neurological outcomes.

\footnotetext{
Abbreviations

2-OGDs: 2-oxoglutarate and Fe (II)-dependent dioxygenases; $5 \mathrm{mc}$ : 5'methylcytosine; ATM: Ataxia telangenctasia mutated protein; CHARGE: Coloboma of the eye, heart defects, atresia of the nasal choanae, retardation of growth and development, genital and urinary abnormalities, and ear abnormalities and deafness; CHD: Chromodomain helicase DNAbinding protein; DNMT: DNA methyltransferases; $\mathrm{H1}$ : Histone 1; H2A: Histone 2A; H2B: Histone 2B; H3: Histone 3; H4: Histone 4; HAT: Histone acetyltransferase; HDAC: Histone deacetylase; HIE: Hypoxic ischemic
}

encephalopathy; HIF1a: Hypoxia inducible factor 1 alpha; K: Lysine; KDM6A: Lysine-specific demethylase 6A; KMT2D: Lysine-specific methyltransferase 2D KMT2D; R: Arginine; TET: Ten-eleven translocation family proteins; WNT: Wingless

\section{Acknowledgements}

We like to thank Dr. Robinson and the IDDRC for suggesting we write this review.

\section{Authors' contributions}

$A C$ and EDM conceived of the review. AC wrote the first draft of the manuscript and EDM edited and contributed to all other drafts. AC and EDM read and approved the final version of the manuscript.

\section{Funding}

AGC is grateful for funding from the NIH (NICHD K12: 5K12HD043245-18) and institutional grants (Foerderer Grant, K-readiness Pilot Grant, and BTTG). EDM had funding by the CHOP/PENN IDDRC P30 (P30 HD026979 25).

Availability of data and materials

Not applicable

Ethics approval and consent to participate Not applicable.

\section{Consent for publication}

Authors consent to publication.

\section{Competing interests}

None for this work.

Received: 5 February 2020 Accepted: 13 November 2020

Published online: 16 December 2020

\section{References}

1. Jauniaux E, Watson AL, Hempstock J, Bao YP, Skepper JN, Burton GJ. Onset of maternal arterial blood flow and placental oxidative stress: A possible factor in human early pregnancy failure. Am J Pathol. 2000;157:2111-22.

2. Panfoli I, Candiano G, Malova M, De Angelis L, Cardiello V, Buonocore G, et al. Oxidative stress as a primary risk factor for brain damage in preterm newborns. Front Pediatr. 2018;6 [cited 2020 Jan 20]. Available from: https:// www.frontiersin.org/article/10.3389/fped.2018.00369/full.

3. Ferriero DM, et al. N Engl J Med. 2004;351:1985-95 Massachusetts Medical Society. [cited 2017 Oct 21]. Available from: http://www.nejm.org/doi/abs/1 0.1056/NEJMra041996.

4. Lawn JE, Cousens S, Zupan J. 4 million neonatal deaths: When? Where? Why? Lancet. 2005;365:891-900 Elsevier. [cited 2018 Oct 20]. Available from: https://proxy.library.upenn.edu:2067/science/article/pii/S0140673605710485 ?via\%3Dihub.

5. Stanaway JD, Afshin A, Gakidou E, Lim SS, Abate D, Abate KH, et al. Global, regional, and national comparative risk assessment of 84 behavioural, environmental and occupational, and metabolic risks or clusters of risks for 195 countries and territories, 1990-2017: a systematic analysis for the Global Burden of Disease Study 2017. Lancet. 2018;392:1923-94 Elsevier. [cited 2019 Jan 1]. Available from: https://proxy.library.upenn.edu:2067/science/ article/pii/S0140673618322256?via\%3Dihub.

6. Hutter D, Kingdom J, Jaeggi E. Causes and Mechanisms of Intrauterine Hypoxia and Its Impact on the Fetal Cardiovascular System: A Review. Int J Pediatr. 2010:2010:1-9 Hindawi Limited.

7. Gopagondanahalli KR, Li J, Fahey MC, Hunt RW, Jenkin G, Miller SL, et al. Preterm hypoxic-ischemic encephalopathy [Internet]. Front Pediatr. 2016:114 Frontiers Media SA. [cited 2019 Sep 5]. Available from: http://www.ncbi.nlm. nih.gov/pubmed/27812521.

8. Malhotra A, Allison BJ, Castillo-Melendez M, Jenkin G, Polglase GR, Miller SL. Neonatal morbidities of fetal growth restriction: Pathophysiology and impact. Front Endocrinol (Lausanne). 2019:10:55. Frontiers Media S.A.

9. Sun H, Juul HM, Jensen FE. Models of hypoxia and ischemia-induced seizures. J Neurosci Methods. 2015; [cited 2015 Oct 19]; Available from: http://www.sciencedirect.com/science/article/pii/S0165027015003568.

10. Janot M, Cortes-Dubly M-L, Rodriquez S, Huynh-Do U. Bilateral uterine vessel ligation as a model of intrauterine growth restriction in mice. Reprod 
Biol Endocrinol. 2014;12:62 BioMed Central. [cited 2016 Sep 18]. Available from: http://rbej.biomedcentral.com/articles/10.1186/1477-7827-12-62.

11. Lawrence KM, McGovern PE, Mejaddam A, Rossidis AC, Baumgarten H, Kim A, et al. Chronic intrauterine hypoxia alters neurodevelopment in fetal sheep. J Thorac Cardiovasc Surg. 2019;157:1982-91 Mosby. [cited 2019 Jul 20]. Available from: https://www-sciencedirect-com.proxy.library.upenn.edu/ science/article/pii/S0022522319300200?via\%3Dihub.

12. Lee AC, Kozuki N, Blencowe H, Vos T, Bahalim A, Darmstadt GL, et al. Intrapartum-related neonatal encephalopathy incidence and impairment at regional and global levels for 2010 with trends from 1990. Pediatr Res. 2013; 74:50-72 Nature Publishing Group. [cited 2018 Feb 24]. Available from: http://www.nature.com/articles/pr2013206.

13. Rice JE, Vannucci RC, Brierley JB. The influence of immaturity on hypoxicischemic brain damage in the rat. Ann Neurol. 1981;9:131-41 [cited 2020 Jan 25]. Available from: http://doi.wiley.com/10.1002/ana.410090206.

14. Aravamuthan BR, Gandham S, Young AB, Rutkove SB. Sex may influence motor phenotype in a novel rodent model of cerebral palsy. Neurobiol Dis. 2020;134 Academic Press Inc..

15. Northington FJ, Chavez-Valdez R, Martin LJ. Neuronal cell death in neonatal hypoxia-ischemia. Ann Neurol. 2011;69:743-58 [cited 2019 Jul 29]. Available from: http://doi.wiley.com/10.1002/ana.22419. John Wiley \& Sons, Ltd.

16. Trivedi SB, Vesoulis ZA, Rao R, Liao SM, Shimony JS, McKinstry RC, et al. A validated clinical MRI injury scoring system in neonatal hypoxic-ischemic encephalopathy. Pediatr Radiol. 2017;47:1491-9 [cited 2019 Apr 11]. Available from: http://ink.springer.com/10.1007/s00247-017-3893-y. Springer Berlin Heidelberg.

17. McClendon E, Shaver DC, Degener-O'Brien K, Gong X, Nguyen T, HoerderSuabedissen A, et al. Transient hypoxemia chronically disrupts maturation of preterm fetal ovine subplate neuron arborization and activity. J Neurosci. 2017;37:11912-29 Society for Neuroscience.

18. McClendon E, Wang K, Degener-O'Brien K, Hagen MW, Gong X, Nguyen T, et al. Transient hypoxemia disrupts anatomical and functional maturation of preterm fetal ovine CA1 pyramidal neurons. J Neurosci. 2019;39:7853-71 [cited 2019 Sep 18]. Available from: http://www.ncbi.nlm.nih.gov/ pubmed/31455661.

19. Hartley I, Elkhoury FF, Heon Shin J, Xie B, Gu X, Gao Y, et al. Long-lasting changes in DNA methylation following short-term hypoxic exposure in primary hippocampal neuronal cultures. PLoS One. 2013;8:e77859 Chiariotti L, editor. Public Library of Science. [cited 2019 Aug 20]; Available from: https://dx.plos.org/10.1371/journal.pone.0077859.

20. Mikati MA, Zeinieh MP, Kurdi RM, Harb SA, El Hokayem JA, Daderian RH, et al. Long-term effects of acute and of chronic hypoxia on behavior and on hippocampal histology in the developing brain. Dev Brain Res. 2005; cited 2019 Aug 20];157:98-102. Available from: http://www.ncbi.nlm.nih. gov/pubmed/15939090.

21. Stricker SH, Köferle A, Beck S. From profiles to function in epigenomics. Nat Rev Genet [Internet]. Nature Publishing Group; 2017 [cited 2019 Aug 20];18: 51-66. Available from: http://www.nature.com/articles/nrg.2016.138.

22. Cusanovich DA, Hill AJ, Aghamirzaie D, Daza RM, Pliner HA, Berletch JB, et al. A Single-Cell Atlas of In Vivo Mammalian Chromatin Accessibility. Cell. 2018;174:1309-1324.e18 Elsevier. [cited 2018 Nov 27]. Available from: http:// www.ncbi.nlm.nih.gov/pubmed/30078704.

23. Hwang JY, Aromolaran KA, Zukin RS. The emerging field of epigenetics in neurodegeneration and neuroprotection. Nat Rev Neurosci. 2017:347-61 [cited 2019 Sep 8]. Available from: http://www.nature.com/articles/nrn.201 7.46. Nature Publishing Group.

24. Ilyas M, Mir A, Efthymiou S, Houlden $H$. The genetics of intellectual disability: advancing technology and gene editing [Internet]. F1000Research. 2019:22 F1000 Research Ltd. [cited 2020 Sep 18]. Available from: https://doi.org/10. 12688/f1000research.16315.1.

25. Yao B, Jin P. Unlocking epigenetic codes in neurogenesis. Genes Dev. 2014; 28:1253-71 2014/06/19. Available from: http://www.ncbi.nlm.nih.gov/ pubmed/24939932.

26. Cantone I, Fisher AG. Epigenetic programming and reprogramming during development. Nat Struct Mol Biol. 2013:282-9.

27. Bernstein BE, Mikkelsen TS, Xie X, Kamal M, Huebert DJ, Cuff J, et al. A bivalent chromatin structure marks key developmental genes in embryonic stem cells. Cell. 2006;125:315-26 2006/04/25. Available from: http://www. ncbi.nlm.nih.gov/pubmed/16630819.

28. Smith ZD, Meissner A. DNA methylation: Roles in mammalian development. Nat Rev Genet. 2013:204-20.
29. Keverne EB, Pfaff DW, Tabansky I. Epigenetic changes in the developing brain: Effects on behavior. Proc Natl Acad Sci; 2015 ;112:6789-6795. National Academy of Sciences. [cited 2019 Sep 14]. Available from: https://www.pnas. org/content/112/22/6789.

30. Trevino AE, Sinnott-Armstrong N, Andersen J, Yoon S-J, Huber N, Pritchard $\mathrm{JK}$, et al. Chromatin accessibility dynamics in a model of human forebrain development. Science. 2020;367 [cited 2020 Jan 25]. Available from: http:// www.ncbi.nlm.nih.gov/pubmed/31974223.

31. Bird A. DNA methylation patterns and epigenetic memory. Genes Dev. 2002;16(1):6-21.

32. Lister R, Mukamel EA, Nery JR, Urich M, Puddifoot CA, Johnson ND, et al. Global epigenomic reconfiguration during mammalian brain development. Science (80- ). 2013;341 American Association for the Advancement of Science.

33. Meissner A, Mikkelsen TS, Gu H, Wernig M, Hanna J, Sivachenko A, et al. Genome-scale DNA methylation maps of pluripotent and differentiated cells. Nature. 2008;454:766-70 2008/07/05. Available from: http://www.ncbi. nlm.nih.gov/pubmed/18600261.

34. Eden $\mathrm{S}$, Cedar $\mathrm{H}$. Role of DNA methylation in the regulation of transcription. Curr Opin Genet Dev. 1994;4:255-9 [cited 2020 Jan 29]. Available from: http://www.ncbi.nlm.nih.gov/pubmed/8032203.

35. Lu F, Zhang Y. Cell totipotency: Molecular features, induction, and maintenance [Internet]. Natl Sci Rev. 2015:217-25 [cited 2020 Jan 1]. Available from: https://academic.oup.com/nsr/article-lookup/doi/10.1093/ nsr/nwv009.

36. Tan L, Shi YG. Tet family proteins and 5-hydroxymethylcytosine in development and disease. Development. 2012;139:1895-902.

37. Kohli RM, Zhang Y. TET enzymes, TDG and the dynamics of DNA demethylation. Nature. 2013:472-9.

38. Hajkova P, Ancelin K, Waldmann T, Lacoste N, Lange UC, Cesari F, et al, Chromatin dynamics during epigenetic reprogramming in the mouse germ line. Nature. 2008:452:877-81 Nature Publishing Group.

39. Hajkova P, Jeffries SJ, Lee C, Miller N, Jackson SP, Surani MA. Genome-wide reprogramming in the mouse germ line entails the base excision repair pathway. Science (80- ). 2010;329:78-82.

40. Nestor CE, Ottaviano R, Reddington J, Sproul D, Reinhardt D, Dunican D, et al. Tissue type is a major modifier of the 5-hydroxymethylcytosine content of human genes. Genome Res. 2012;22:467-77.

41. Spiers H, Hannon E, Schalkwyk LC, Smith R, Wong CCY, O'Donovan MC, et al. Methylomic trajectories across human fetal brain development. Genome Res. 2015;25:338-52 Cold spring harbor laboratory press.

42. Spiers H, Hannon E, Schalkwyk LC, Bray NJ, Mill J. 5-hydroxymethylcytosine is highly dynamic across human fetal brain development. BMC Genomics. 2017;18 BioMed Central Ltd.

43. Guo JU, Su Y, Shin JH, Shin J, Li H, Xie B, et al. Distribution, recognition and regulation of non- $\mathrm{CpG}$ methylation in the adult mammalian brain. Nat Neurosci. 2014:17:215-22.

44. He Y, Ecker JR. Non-CG Methylation in the Human Genome. Annu Rev Genomics Hum Genet. 2015;16:55-77 [cited 2020 Jan 25]. Available from: http://www.annualreviews.org/doi/10.1146/annurev-genom-090413-025437.

45. Kinde B, Gabel HW, Gilbert CS, Griffith EC, Greenberg ME. Reading the unique DNA methylation landscape of the brain: Non-CpG methylation, hydroxymethylation, and MeCP2. Proc Natl Acad Sci U S A. 2015;112:6800-6 National Academy of Sciences.

46. Mellor J. The dynamics of chromatin remodeling at promoters. Mol Cell. 2005;19:147-57 [cited 2017 Jul 25]. Available from: http://www.ncbi.nlm.nih. gov/pubmed/16039585.

47. Lee KK, Workman JL. Histone acetyltransferase complexes: One size doesn't fit all. Nat Rev Mol Cell Biol. 2007:284-95.

48. Jambhekar A, Dhall A, Shi Y. Roles and regulation of histone methylation in animal development. Nat Rev Mol Cell Biol. 2019:625-41 Nature Publishing Group.

49. Krumm N, O'Roak BJ, Shendure J, Eichler EE. A de novo convergence of autism genetics and molecular neuroscience [Internet]. Trends Neurosci. 2014;95:105 [cited 2019 Dec 10]. Available from: https://www-sciencedirect-com.proxy. library.upenn.edu/science/article/pii/S0166223613002257?via\%3Dihub.

50. Su Y, Shin J, Zhong C, Wang S, Roychowdhury P, Lim J, et al. Neuronal activity modifies the chromatin accessibility landscape in the adult brain. Nat Neurosci. 2017;20:476-83 Nature Publishing Group.

51. Beagan JA, Pastuzyn ED, Fernandez LR, Guo MH, Feng K, Titus KR, et al. Three-dimensional genome restructuring across timescales of activityinduced neuronal gene expression. Nat Neurosci. 2020. 
52. Tatton-Brown K, Seal S, Ruark E, Harmer J, Ramsay E, Del Vecchio DS, et al. Mutations in the DNA methyltransferase gene DNMT3A cause an overgrowth syndrome with intellectual disability. Nat Genet. 2014;46:385-8 Nature Publishing Group.

53. Feng J, Chang H, Li E, Fan G. Dynamic expression of de novo DNA methyltransferases Dnmt3a and Dnmt3b in the central nervous system. J Neurosci Res. 2005;79:734-46 [cited 2019 Dec 30]. Available from: http://doi. wiley.com/10.1002/jnr.20404.

54. Feng J, Zhou Y, Campbell SL, Le T, Li E, Sweatt JD, et al. Dnmt1 and Dnmt3a maintain DNA methylation and regulate synaptic function in adult forebrain neurons. Nat Neurosci. 2010;13:423-30.

55. Jin B, Tao Q, Peng J, Soo HM, Wu W, Ying J, et al. DNA methyltransferase 3B (DNMT3B) mutations in ICF syndrome lead to altered epigenetic modifications and aberrant expression of genes regulating development, neurogenesis and immune function. Hum Mol Genet. 2008;17:690-709 [cited 2020 Jan 25]. Available from: https://academic.oup.com/hmg/articlelookup/doi/10.1093/hmg/ddm341.

56. Meehan R, Lewis JD, Bird AP. Characterization of MECP2, a vertebrate DNA binding protein with affinity for methylated DNA. Nucleic Acids Res. 1992; 20:5085-92

57. Chahrour M, Zoghbi HY. The Story of Rett Syndrome: From Clinic to Neurobiology. Neuron. 2007:422-37.

58. Schnetz MP, Handoko L, Akhtar-Zaidi B, Bartels CF, Pereira CF, Fisher AG, et al. CHD7 targets active gene enhancer elements to modulate ES cellspecific gene expression. PLoS Genet. 2010 ;6:e1001023 van Heyningen V, editor. [cited 2019 Dec 31]. Available from: https://dx.plos.org/10.1371/ journal.pgen.1001023.

59. Feng W, Khan MA, Bellvis P, Zhu Z, Bernhardt O, Herold-Mende C, et al. The chromatin remodeler CHD7 regulates adult neurogenesis via activation of soxc transcription factors. Cell Stem Cell. 2013;13:62-72 Cell Press.

60. Nishiyama M, Oshikawa K, Tsukada YI, Nakagawa T, lemura SI, Natsume T, et al. CHD8 suppresses p53-mediated apoptosis through histone $\mathrm{H} 1$ recruitment during early embryogenesis. Nat Cell Biol. 2009;11:172-82.

61. Nishiyama M, Skoultchi Al, Nakayama KI. Histone H1 Recruitment by CHD8 is essential for suppression of the Wnt- -catenin signaling pathway. Mol Cell Biol. 2012;32:501-12 American Society for Microbiology.

62. Fergelot P, Van Belzen M, Van Gils J, Afenjar A, Armour CM, Arveiler B, et al. Phenotype and genotype in 52 patients with Rubinstein-Taybi syndrome caused by EP300 mutations. Am J Med Genet Part A. 2016;170:3069-82 Wiley-Liss Inc.

63. Lipinski M, del Blanco B, Barco A. CBP/p300 in brain development and plasticity: disentangling the KAT's cradle. Curr Opin Neurobiol. 2019:1-8 Elsevier Ltd.

64. Hecht A, Vleminckx K, Stemmler MP, van Roy F, Kemler R. The p300/CBP acetyltransferases function as transcriptional coactivators of beta-catenin in vertebrates. EMBO J. 2000;19:1839-50 Available from: http://www.ncbi.nlm. nih.gov/entrez/query.fcgi?cmd=Retrieve\&db=PubMed\&dopt=Citation\&list_ uids $=10775268$.

65. Williams SR, Aldred MA, Der Kaloustian VM, Halal F, Gowans G, McLeod DR, et al. Haploinsufficiency of HDAC4 causes brachydactyly mental retardation syndrome, with brachydactyly type E, developmental delays, and behavioral problems. Am J Hum Genet. 2010;87:219-28.

66. Kondratenko IV, Suspitsin EN, Vakhlyarskaya SS, Bologov AA, Imyanitov EN. Kabuki syndrome. GeneReviews [Internet], vol. 16; 2017. p. 75-83. [cited 2019 Dec 31]. Available from: http://www.ncbi.nlm.nih.gov/pubmed/21882399.

67. Bale TL. Epigenetic and transgenerational reprogramming of brain development. Nat Rev Neurosci. 2015:332-44 Nature Publishing Group.

68. Semenza GL, et al. Annu Rev Pathol Mech Dis. 2014;9:47-71 [cited 2019 Dec 31]. Available from: http://www.annualreviews.org/doi/10.1146/annurevpathol-012513-104720

69. Chen W, Jadhav V, Tang J, Zhang JH. HIF-1a inhibition ameliorates neonatal brain injury in a rat pup hypoxic-ischemic model. Neurobiol Dis. 2008;31: 433-41 Academic Press. [cited 2019 Aug 21]. Available from: https://wwwsciencedirect-com.proxy.library.upenn.edu/science/article/pii/S09699961 08001241 ?via\%3Dihub.

70. Sheldon RA, Osredkar D, Lee CL, Jiang X, Mu D, Ferriero DM. HIF-1 alphadeficient mice have increased brain injury after neonatal hypoxia-ischemia. Dev Neurosci. 2009:31:452-8 Karger Publishers. [cited 2017 Oct 12]. Available from: http://www.ncbi.nlm.nih.gov/pubmed/19672073.

71. Watson JA, Watson CJ, Mccann A, Baugh J. Epigenetics, the epicenter of the hypoxic response. Epigenetics. 2010;5:293-6 Taylor and Francis Inc.
72. Hancock RL, Dunne K, Walport L, Flashman E, Kawamura A. Epigenetic regulation by histone demethylases in hypoxia. Epigenomics. 2015:791-811 Future Medicine Ltd.

73. Semenza GL. Regulation of metabolism by hypoxia-inducible factor 1. Cold Spring Harb Symp Quant Biol. 2011;76:347-53 Cold Spring Harbor Laboratory Press. [cited 2018 Apr 22]. Available from: http://www.ncbi.nlm. nih.gov/pubmed/21785006.

74. Li C, Xiong W, Liu X, Xiao W, Guo Y, Tan J, et al. Hypomethylation at non$\mathrm{CpG} / \mathrm{CpG}$ sites in the promoter of HIF-1a gene combined with enhanced H3K9Ac modification contribute to maintain higher HIF-1a expression in breast cancer. Oncogenesis. 2019;8 Nature Publishing Group.

75. Robinson CM, Lefebvre F, Poon BP, Bousard A, Fan X, Lathrop M, et al. Consequences of VHL Loss on Global DNA Methylome. Sci Rep. 2018;8 Nature Publishing Group.

76. Xia O, Lemieux ME, Li W, Carroll JS, Brown M, Shirley Liu X, et al. Integrative analysis of HIF binding and transactivation reveals its role in maintaining histone methylation homeostasis. Proc Natl Acad Sci U S A. 2009;106:4260-5.

77. Hu X-Q, Chen M, Dasgupta C, Xiao D, Huang X, Yang S, et al. Chronic hypoxia upregulates DNA methyltransferase and represses large conductance $\mathrm{Ca}$ 2+-activated $\mathrm{K}+$ channel function in ovine uterine arteriest. Biol Reprod. 2017;96:424-34 [cited 2019 Dec 31]. Available from: https:// academic.oup.com/biolreprod/article/96/2/424/2889001.

78. Childebayeva A, Harman T, Weinstein J, Goodrich JM, Dolinoy DC, Day TA, et al. Dna methylation changes are associated with an incremental ascent to high altitude. Front Genet. 2019;10 Frontiers Media S.A.

79. Palma-Gudiel H, Eixarch E, Crispi F, Morán S, Zannas AS, Fañanás L. Prenatal adverse environment is associated with epigenetic age deceleration at birth and hypomethylation at the hypoxia-responsive EP300 gene. Clin Epigenetics. 2019;11 BioMed Central Ltd.

80. Li Y, Ma Q, Halavi S, Concepcion K, Hartman RE, Obenaus A, et al. Fetal stress-mediated hypomethylation increases the brain susceptibility to hypoxic-ischemic injury in neonatal rats. Exp Neurol. 2016;275:1-10 Academic Press Inc. [cited 2019 Dec 30]. Available from: https://www.ncbi. nlm.nih.gov/pubmed/26597542.

81. Großer E, Hirt U, Janc OA, Menzfeld C, Fischer M, Kempkes B, et al. Oxidative burden and mitochondrial dysfunction in a mouse model of Rett syndrome. Neurobiol Dis. 2012;48:102-14.

82. Turovsky E, Karagiannis A, Abdala AP, Gourine AV. Impaired CO2 sensitivity of astrocytes in a mouse model of Rett syndrome. J Physiol. 2015;593:315968 Blackwell Publishing Ltd.

83. Kron M, Müller M. Impaired hippocampal Ca2+ homeostasis and concomitant $\mathrm{K}+$ channel dysfunction in a mouse model of rett syndrome during anoxia. Neuroscience. 2010;171:300-15.

84. De Felice C, Signorini C, Leoncini S, Pecorelli A, Durand T, Valacchi G, et al. The role of oxidative stress in Rett syndrome: an overview. Ann N Y Acad Sci. 2012;1259:121-35 Blackwell Publishing Inc. [cited 2020 Oct 11]. Available from: http://doi.wiley.com/10.1111/j.1749-6632.2012.06611.x.

85. Neul JL, Skinner SA, Annese F, Lane J, Heydemann P, Jones M, et al. Metabolic signatures differentiate Rett syndrome from unaffected siblings. Front Integr Neurosci. 2020;14:7 Frontiers Media S.A. [cited 2020 Oct 11]. Available from: https:/www.frontiersin.org/article/10.3389/fnint.2020.00007/full.

86. Peebles PJ, Duello TM, Eickhoff JC, MCAdams RM. Antenatal and intrapartum risk factors for neonatal hypoxic ischemic encephalopathy. J Perinatol. 2019; Nature Publishing Group

87. Gonzalez-Rodriguez PJ, Xiong F, Li Y, Zhou J, Zhang L. Fetal hypoxia increases vulnerability of hypoxic-ischemic brain injury in neonatal rats: Role of glucocorticoid receptors. Neurobiol Dis. 2014;65:172-9.

88. Stowe AM, Altay T, Freie AB, Gidday JM. Repetitive hypoxia extends endogenous neurovascular protection for stroke. Ann Neurol. 2011;69:975-85 [cited 2020 Jan 29]. Available from: http://doi.wiley.com/10.1002/ana.22367.

89. Jung BP, Zhang G, Ho W, Francis J, Eubanks JH. Transient forebrain ischemia alters the mRNA expression of methyl DNA-binding factors in the adult rat hippocampus. Neuroscience. 2002;115:515-24 Pergamon.

90. Rosenberg EC, Lippman-Bell JJ, Handy M, Soldan SS, Rakhade S, HilarioGomez C, et al. Regulation of seizure-induced MeCP2 Ser421 phosphorylation in the developing brain. Neurobiol Dis. 2018;116:120-30 Academic Press Inc. [cited 2020 Jan 1]. Available from: https://www.ncbi. nlm.nih.gov/pubmed/29738885.

91. Zhou Z, Hong EJ, Cohen S, Zhao W, Ho HYH, Schmidt L, et al. Brain-specific phosphorylation of mecp2 regulates activity-dependent Bdnf transcription, dendritic growth, and spine maturation. Neuron. 2006;52:255-69. 
92. Boyd NH, Walker K, Ayokanmbi A, Gordon ER, Whetsel J, Smith CM, et al. Chromodomain helicase DNA-binding protein 7 is suppressed in the perinecrotic/ischemic microenvironment and is a novel regulator of glioblastoma angiogenesis. Stem Cells. 2019;37:453-62 [cited 2019 Dec 31]. Available from: http://doi.wiley.com/10.1002/stem.2969.

93. Carosso GA, Boukas L, Augustin JJ, Nguyen HN, Winer BL, Cannon GH, et al. Precocious neuronal differentiation and disrupted oxygen responses in Kabuki syndrome. JCI Insight. 2019;4 American Society for Clinical Investigation. [cited 2019 Dec 31]. Available from: https:/insight.jci.org/ articles/view/129375.

94. Maltepe E, Krampitz GW, Okazaki KM, Red-Horse K, Mak W, Simon MC, et al. Hypoxia-inducible factor-dependent histone deacetylase activity determines stem cell fate in the placenta. Development. 2005;132:3393-403.

95. Jaworska J, Zalewska T, Sypecka J, Ziemka-Nalecz M. Effect of the HDAC inhibitor, sodium butyrate, on neurogenesis in a rat model of neonatal hypoxia-ischemia: potential mechanism of action. Mol Neurobiol. 2019;56: 6341-70 Humana Press Inc.

96. Säemann MD, Böhmig GA, Osterreicher $\mathrm{CH}$, Burtscher $\mathrm{H}$, Parolini O, Diakos $C$, et al. Anti-inflammatory effects of sodium butyrate on human monocytes: potent inhibition of IL-12 and up-regulation of IL-10 production. FASEB J. 2000;14:2380-2

97. Batie M, Frost J, Frost M, Wilson JW, Schofield P, Rocha S. Hypoxia induces rapid changes to histone methylation and reprograms chromatin. Science (80- ). 2019;363:1222-6 American Association for the Advancement of Science.

98. Ozer A, Bruick RK. Non-heme dioxygenases: Cellular sensors and regulators jelly rolled into one? Nat Chem Biol. 2007:144-53 Nature Publishing Group.

99. Chakraborty AA, Laukka T, Myllykoski M, Ringel AE, Booker MA, Tolstorukov MY, et al. Histone demethylase KDM6A directly senses oxygen to control chromatin and cell fate. Science (80- ). 2019;363:1217-22 American Association for the Advancement of Science.

100. Müller S, Krämer OH. Inhibitors of HDACs--effective drugs against cancer? Curr Cancer Drug Targets. 2010;10:210-28 [cited 2011 May 25]. Available from: http://www.ncbi.n/m.nih.gov/pubmed/20201785.

101. Gaulton KJ, Nammo T, Pasquali L, Simon JM, Giresi PG, Fogarty MP, et al. A map of open chromatin in human pancreatic islets. Nat Genet. 2010;42:2559 Available from: http://www.ncbi.nlm.nih.gov/entrez/query.fcgi?cmd= Retrieve\&db=PubMed\&dopt=Citation\&list_uids $=20118932$.

102. Everson TM, Marsit CJ, Michael O'Shea T, Burt A, Hermetz K, Carter BS, et al. Epigenome-wide analysis identifies genes and pathways linked to neurobehavioral variation in preterm infants. Sci Rep. 2019;9 Nature Publishing Group.

103. Mohandas N, Bass-Stringer S, Maksimovic J, Crompton K, Loke YJ, Walstab J, et al. Epigenome-wide analysis in newborn blood spots from monozygotic twins discordant for cerebral palsy reveals consistent regional differences in DNA methylation. Clin Epigenetics. 2018;10:25 [cited 2019 Dec 30]. Available from: https://clinicalepigeneticsjournal.biomedcentral.com/articles/10.1186/ s13148-018-0457-4.

104. Horvath S, Raj K. DNA methylation-based biomarkers and the epigenetic clock theory of ageing. Nat Rev Genet. 2018:371-84 Nature Publishing Group.

105. McEwen LM, O'Donnell KJ, McGill MG, Edgar RD, Jones MJ, Maclsaac JL, et al. The PedBE clock accurately estimates DNA methylation age in pediatric buccal cells. Proc Natl Acad Sci. 2019:201820843 Proceedings of the National Academy of Sciences.

106. Knight AK, Craig JM, Theda C, Bækvad-Hansen M, Bybjerg-Grauholm J, Hansen CS, et al. An epigenetic clock for gestational age at birth based on blood methylation data. Genome Biol. 2016;17:206 [cited 2019 Dec 31]. Available from: http://genomebiology.biomedcentral.com/articles/10.1186/ s13059-016-1068-z.

107. Cao-Lei L, Massart R, Suderman MJ, Machnes Z, Elgbeili G, Laplante DP, et al. DNA methylation signatures triggered by prenatal maternal stress exposure to a natural disaster: project ice storm. PLoS One. 2014;9:e107653 Iwamoto K, editor. [cited 2019 Dec 30]. Available from: https://dx.plos.org/10.1371/ journal.pone.0107653.

108. Berdasco M, Esteller M. Clinical epigenetics: seizing opportunities for translation. Nat Rev Genet. 2019;20:109-27 Nature Publishing Group. [cited 2019 Sep 7]. Available from: http://www.nature.com/articles/s41576-0180074-2.

109. Bjornsson HT, Benjamin JS, Zhang L, Weissman J, Gerber EE, Chen Y-C, et al. Histone deacetylase inhibition rescues structural and functional brain deficits in a mouse model of Kabuki syndrome. Sci Transl Med. 2014;6: 256ra135 [cited 2019 Sep 8]. Available from: http://stm.sciencemag.org/cgi/ doi/10.1126/scitransImed.3009278.

110. Katz DM, Bird A, Coenraads M, Gray SJ, Menon DU, Philpot BD, et al. Rett syndrome: crossing the threshold to clinical translation [Internet]. Trends Neurosci. 2016 100-113. [cited 2019 Sep 8]. Elsevier Current Trends. Available from: https://www-sciencedirect-com.proxy.library.upenn.edu/ science/article/pii/S0166223615002829?via\%3Dihub.

111. Fernandes J, Arida RM, Gomez-Pinilla F. Physical exercise as an epigenetic modulator of brain plasticity and cognition. Neurosci Biobehav Rev. 2017: 443-56 Elsevier Ltd.

112. Liu PZ, Nusslock R. Exercise-Mediated Neurogenesis in the Hippocampus via BDNF. Front Neurosci. 2018;12 [cited 2020 Jan 25]. Available from: http:// journal.frontiersin.org/article/10.3389/fnins.2018.00052/full.

113. Hashimoto T, Bergen SE, Nguyen QL, Xu B, Monteggia LM, Pierri JN, et al. Relationship of brain-derived neurotrophic factor and its receptor TrkB to altered inhibitory prefrontal circuitry in schizophrenia. J Neurosci. 2005;25: 372-83 Available from: http://www.ncbi.nlm.nih.gov/entrez/query.fcgi?cmd= Retrieve\&db=PubMed\&dopt=Citation\&list_uids $=15647480$.

114. Göttlicher M, Minucci S, Zhu P, Krämer OH, Schimpf A, Giavara S, et al. Valproic acid defines a novel class of HDAC inhibitors inducing differentiation of transformed cells. EMBO J. 2001;20:6969-78.

115. Bollino D, Balan I, Aurelian L. Valproic acid induces neuronal cell death through a novel calpain-dependent necroptosis pathway. J Neurochem. 2015;133:174-86 [cited 2020 Jan 2]. Available from: http://doi.wiley.com/1 0.1111/jnc.13029.

116. Kabakus N, Ay I, Aysun S, Söylemezoglu F, Ozcan A, Celasun B. Protective effects of valproic acid against hypoxic-ischemic brain injury in neonatal rats. J Child Neurol. 2005;20:582-7 [cited 2020 Jan 2]. Available from: http:// www.ncbi.nlm.nih.gov/pubmed/16159524.

117. Eun HK, Hee SK, Kim SU, Eun JN, Lee JS, Choi KS. Sodium butyrate sensitizes human glioma cells to TRAIL-mediated apoptosis through inhibition of Cdc2 and the subsequent downregulation of survivin and XIAP. Oncogene. 2005;24:6877-89.

118. Morris-Blanco KC, Kim T, Lopez MS, Bertogliat MJ, Chelluboina B, Vemuganti R. Induction of DNA Hydroxymethylation Protects the Brain After Stroke. Stroke. 2019;50:2513-21 [cited 2019 Dec 30]. Available from: http://www. ncbi.nlm.nih.gov/pubmed/31327315.

\section{Publisher's Note}

Springer Nature remains neutral with regard to jurisdictional claims in published maps and institutional affiliations.
Ready to submit your research? Choose BMC and benefit from:

- fast, convenient online submission

- thorough peer review by experienced researchers in your field

- rapid publication on acceptance

- support for research data, including large and complex data types

- gold Open Access which fosters wider collaboration and increased citations

- maximum visibility for your research: over $100 \mathrm{M}$ website views per year

At BMC, research is always in progress.

Learn more biomedcentral.com/submissions 